\title{
Assessment of outdoor thermal comfort and its relation to urban geometry
}

\author{
R. Cocci Grifoni ${ }^{1}$, G. Passerini ${ }^{2} \&$ M. Pierantozzi ${ }^{2}$ \\ ${ }^{1}$ School of Architecture and Design, Camerino University, Italy \\ ${ }^{2}$ Department of Energetics, Marche Politechnic University, Italy
}

\begin{abstract}
Microclimate conditions in urban open spaces are directly linked to the configuration of street axes and building heights and their attributes. Within street canyons, public places, and open spaces, the local microclimate depends directly on the physical properties of the surrounding surfaces and objects, producing well-known effects that can decrease or increase thermal loads. All of these phenomena can greatly influence the comfort of a city and the thermal comfort of pedestrians. Thermal comfort is an indicator that cannot be easily converted into physical parameters. However, it may be defined more qualitatively as the range of climatic conditions in which most people feel comfortable. One well-recognized thermal comfort index used to measure comfort levels inside a space is the predicted mean vote (PMV). Fanger's PMV index has been widely used in the last ten years. It is based on six factors: air temperature, air speed, humidity, mean radiant temperature, metabolic rate, and clothing levels. The comfort equation establishes relationships among the abovementioned environmental variables, clothing type, and metabolic rate. The authors present results of PMV simulations using a multi-objective optimization tool (i.e., modeFrontier). ModeFRONTIER is an integration platform used to optimize and arrange PMV algorithms linked to urban geometry parameters (e.g., the height-to-width (H/W) ratio of urban streets). The optimization process employs given constraints, custom procedural algorithms, and genetic algorithms to examine a wide urban space and identify interesting relationships among the variables considered. Urban geometry, meteorological data, and latent influences are examined and negotiated quantitatively to improve outdoor thermal comfort. Keywords: predicted mean vote, predicted percentage of dissatisfied, outdoor thermal comfort, multi-objective optimization.
\end{abstract}




\section{Introduction}

Outdoor public spaces have become the heart of civic life in the city where people carry out their activities and leisure. It is well known that improving the quality of life in urban centres does require not only efficient buildings, but also climatically sensitive urban public spaces that can enhance and enrich urban life.

Recent worldwide studies [1] have indicated the influence of densely built urban areas on the formation of urban climate conditions as well as on the determination of the microclimate. The influence of urban geometry on the microclimate and human comfort in urban spaces is a very important aspect to consider when estimating outdoor comfort. In addition, the climate of the outdoor urban space has important effects on the energy consumption of cities, and the processes that create these climates are very complex. Therefore, the most precise way to calculate or assess the impact of changes is to use numerical methods (several models already exist), which are able to deal with the complexity of urban structures and even take into account human thermal comfort.

In this study, the PMV thermal comfort index [2] was used and its diurnal variation assessed by introducing the representative day technique in order to obtain information on correlations between thermal comfort and meteorological parameters.

The Representative Day (RD) [3] is determined by the actual data of the day in the period considered, where the sum of the mean-square differences among its monitored quantities averaged within each hour, and the same quantities for all other days at the same hour, is minimised.

The microclimate analysis of an urban space must consider all meteorological conditions such as solar incidence and radiation exchanges, local wind characteristics, topography, vegetation and the presence of water. Beyond these factors, the urban design, the morphology of the buildings, and the behaviour of individuals are also factors that influence the thermal conditions of the outdoor spaces considered.

The city of Ancona was chosen as case study because it represents a typical example of Mediterranean city located in central Italy (namely Marche region), characterized by long, hot summers and mild winters. The investigations in this study are almost exclusively limited to the summer period (June to September) throughout a meteorological data series (2009-2012) because climatic hot-stress in urban open spaces mainly occurs during this season of the year.

In particular, this paper builds upon recent work in parametric optimization in order to assess the outdoor thermal comfort in urban spaces. Specifically, a new tool has been developed using a powerful environment for symbolic and numerical computing and data visualization (Wolfram Mathematica TM), aiming at linking information computed in a bio-climate model to the representative day technique using a parametric optimization with different algorithms (e.g., Simplex and genetic algorithms). 


\section{Outdoor thermal comfort}

\subsection{PMV thermal comfort index}

Thermal comfort is defined in the ISO 7730 [4] as "The condition of mind that expresses satisfaction with the thermal environment". It is an indicator that cannot be easily converted into physical parameters. However, thermal comfort can be defined more qualitatively as the range of climatic conditions in which most people feel comfortable. The most widely used thermal comfort index is the predicted mean vote (PMV) index, which was developed by Fanger and Toftum [5]. Fanger states that two conditions must be achieved to maintain thermal comfort. The first is the real resultant of skin temperature and the body's core temperature, which provides a sensation of thermal neutrality. The second is the realization of the body's energy balance, which is based on the conservation of energy:

$$
M+W+R+C+E_{D}+E_{R D}+E_{S W}+S=0
$$

where $M$ is the metabolic rate (internal energy production), $W$ is the physical work output, $R$ is the net radiation of the body, $C$ is the convective heat flow, ED is the latent heat flow to evaporate water diffusing through the skin, $E R D$ is the sum of heat flows for heating and humidifying the inhaled air, ESW is the heat flow due to evaporation of sweat, $S$ is the storage heat flow for heating or cooling the body mass.

Fanger has derived a comfort equation from the equation for heat balance. It is a function of six parameters that influence thermal comfort. In fact, PMV is a function of two human variables and four environmental variables: clothing insulation, human activity, air temperature, air relative humidity, air velocity and mean radiant temperature. The values of the PMV index have a range from -3 to +3 , which corresponds to the occupant's feeling, from cold to hot, while the PMV null value represents a neutral sensation. The thermal stress established by the PMV is based on the steady state of heat transfer between the body and the environment. It is an empirical equation used to evaluate the mean vote on a rating scale of thermal comfort of a large population of people. To develop a curve and get average results, people were exposed to different environments at different spans of time. The term PPD represents the predicted percentage of people dissatisfied at each PMV. The predicted distribution of votes is given in Table 1.

Table 1: Distribution of individual thermal sensation for different values of mean vote [4].

\begin{tabular}{|l|l|l|l|l|}
\hline \multirow{2}{*}{ PMV } & PPD & \multicolumn{4}{|l|}{ People predicted to vote $(\%)$} \\
\cline { 3 - 5 } & & 0 & $-1,0$ or +1 & $-2,-1,0,+1$ or +2 \\
\hline+2 & 75 & 5 & 25 & 70 \\
\hline+1 & 25 & 30 & 75 & 95 \\
\hline+0.5 & 10 & 55 & 90 & 98 \\
\hline 0 & 5 & 60 & 95 & 100 \\
\hline-0.5 & 10 & 55 & 90 & 98 \\
\hline-1 & 25 & 30 & 75 & 95 \\
\hline-2 & 75 & 5 & 25 & 70 \\
\hline
\end{tabular}


The value of PPD increases whenever PMV absolute value increases i.e. it moves from zero. A curve has been developed to predict the percentage of people dissatisfied as a function of Predicted Mean Vote (Fig. 1).

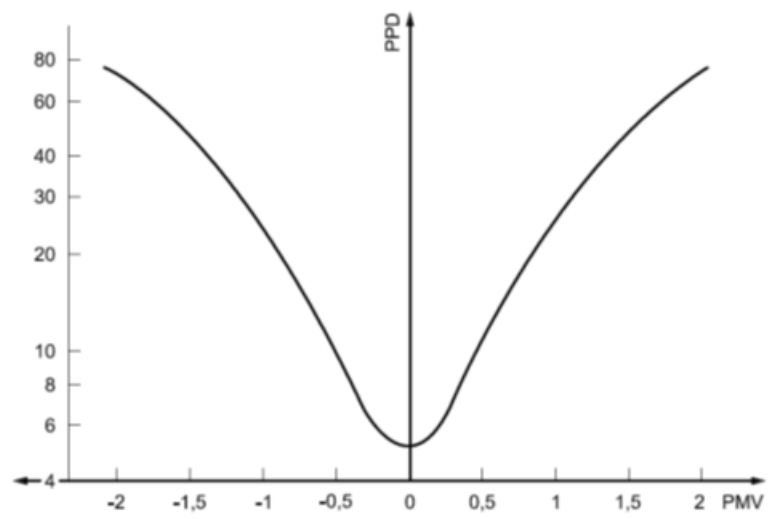

Figure 1: Predicted Percentage of Dissatisfied (PPD) as a function of Predicted Mean Vote (PMV) [4].

\subsection{Urban morphology}

Urban geometry determines the ability of natural light to reach building surfaces and the possibility of using natural ventilation within homes; hence, it acts directly on the urban microclimate, influencing the energy consumption of individual buildings and the entire urban organism. In recent years, much research and many applications have looked at the energetic efficiency of buildings and explored the idea of integrating architecture and renewable energy. In contrast, issues related to phenomena in the urban scale have not been studied sufficiently, nor have relationships between the small and large scales. Synergistic relationships between individual buildings and urban spaces have not been sufficiently investigated from a systemic viewpoint, nor has a shared view on the relationships between urban form, energetic efficiency of the city, and quality of life been developed. Today, there is no shared theory that is applicable and usable by planners. What emerges, however, is the need for a close transdisciplinary comparison, since there are many parameters to consider in urban sustainability, and these include in particular, meteorological parameters, building height, urban density and the system of open and green spaces.

The character of a city or a built environment is described in relation to its built form and level of social activities, both of which, therefore, should be included in urban spaces. In addition, the city and its public spaces can only be built in the form of streets, squares, and blocks of familiar dimensions and character [6]. All of these elements should be integrated appropriately to create better urban spaces. Blocks consist of buildings, and streets and squares are defined by blocks. The character of each of these elements affects the perception 
of the urban space. The width of the street, the height and size of the blocks, etc., are just a few factors that contribute to the urban space. Recent studies around the world have indicated the strong influence of densely built urban areas on the formation of urban climate conditions and particularly on the determination of the microclimate.

The outdoor thermal environment is impacted by the built environment, e.g., building dimensions, street weight, anthropogenic heat, evaporation and evapotranspiration of plants, shading by trees, and so on. In an urban context, building density increases substantially.

Today, more than half of the Earth's inhabitants live in urbanized areas, and this phenomenon is destined to grow. Urbanization forces cities' boundaries to expand, and the urban fabric to become denser. In general, new constructions take the form of tall building structures along relatively narrow streets. As a consequence of the altered heat balance, the air temperatures in densely built urban areas are generally higher than in the surrounding rural hinterland, a phenomenon known as the "Urban Heat Island" (UHI). The heat island is the most obvious climatic manifestation of urbanization [7]. Several causes for the UHI phenomenon were identified by Oke [8], and their relative importance was examined in some studies, [9-11] as an example the reduced convective heat removal due to the reduction of wind speed and the trapping of short- and longwave radiation between buildings. It is well known that urban areas without high climatic quality use more energy for air conditioning in summer as well as more electricity for lighting. Moreover, discomfort and inconvenience to the urban population due to high temperatures, wind tunnel effects in streets, and unusual wind turbulence due to incorrectly designed high-rise buildings is very common. As consequence, it is very important to improve outdoor comfort and reduce high temperatures in urban areas. Climate measurements from urban and suburban stations, as well as specific measurements performed in urban canyons in Athens, Greece, revealed a doubling of the cooling load of urban buildings and a tripling of the peak electricity load for cooling, while the minimum COP (Coefficient of Performance) value of air conditioners decreased up to $25 \%$ because of the higher ambient temperatures [12].

\section{Parametric optimization}

ModeFRONTIER is a multi-objective and multidisciplinary software that allows for statistical analysis and minimization with various techniques.

The optimization process guided by modeFRONTIER therefore allows climatic and spatial conditions guaranteeing PMV minimization and identification of the related PPD to be determined. While climate variables are easy to understand because they come from the ranking in the calculation of the representative day, spatial variables can be varied to minimize discomfort effectively and therefore optimize comfort.

In general, the optimization can be single-objective or multi-objective. The attempt to optimize a project or system in which a single objective is present usually means applying methods to the gradient in which the algorithms look for 
the minimum or maximum of a function according to the established objective. One of the methods for managing multi-objective optimization consists in summing all of the objectives (adequately weighted) into a unique function in order to reduce the problem to a single-objective optimization problem. This method, however, has the disadvantage that such weights, which should be furnished a priori by the user, influence the solution. In addition, if the objectives are all different, it could be difficult or even useless to try to formulate a singleobjective function.

Multi-objective optimization techniques sidestep these problems by keeping the objectives separated within the optimization process. The role of the optimization algorithm consists in identifying solutions that are found on the trade-off curve, better known as the Pareto frontier. A common characteristic of such solutions is the fact that by improving one objective, at least one of the other objectives worsens.

Figures 2 and 3 show scatter plots related to the PMV and PPD generated in

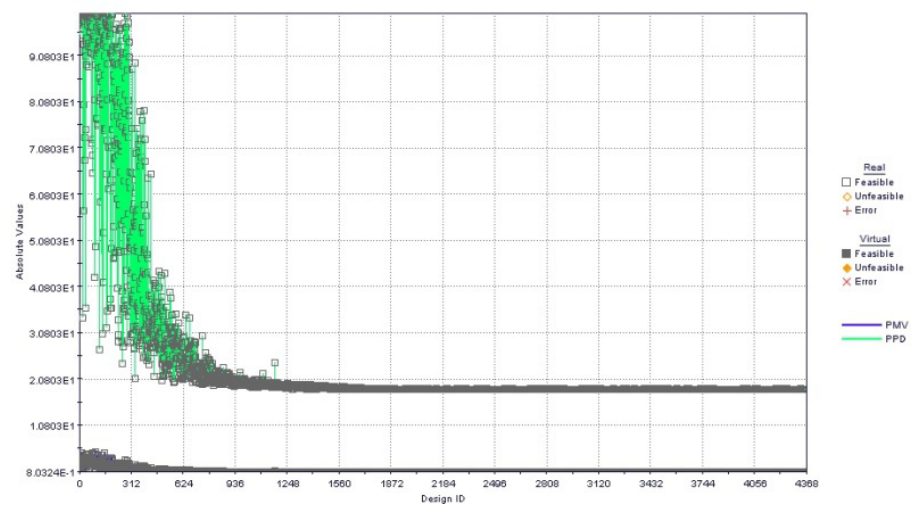

Figure 2: $\quad$ Simultaneous trends of the PMV and PPD.

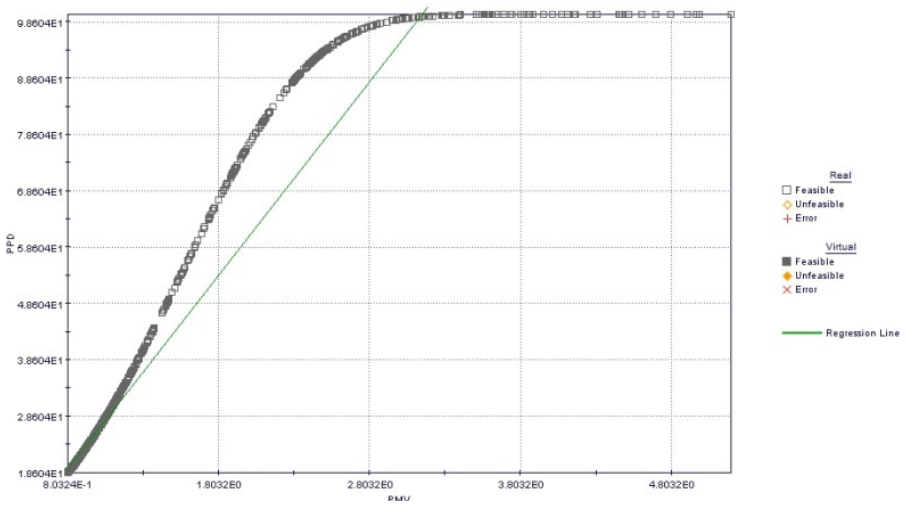

Figure 3: $\quad$ Pareto frontier of optimal solutions in PMV-PPD analysis. 
the optimization process made by modeFRONTIER. Such graphs associate pairs of objectives that the optimization process aims to minimize.

Each point on the graph represents a solution analyzed during the optimization process; the solutions are situated on the Pareto frontier of optimal solutions, which emerges from the scatter plot. The simultaneous convergence to the minimum value can be seen from their asymptotic behaviour.

\subsection{Factor analysis}

Factor analysis is a statistical technique that allows a decrease in the complexity of the number of variables that explain a phenomenon to be obtained.

The effect is just to show the importance of the variation of a certain property (or product of them) with respect to the PMV or PPD. It may be negative whenever it leads to an inverse or positive if there is a direct proportion between the factor considered and the output variable. The input variables taken into account are: temperature, street width, building height, mean radiant temperature, wind speed and relative humidity.

The output variables are PMV and PPD. The coefficients of the best-fitting polynomial are clearly displayed in the factor analysis chart parameters table (Fig. 4).

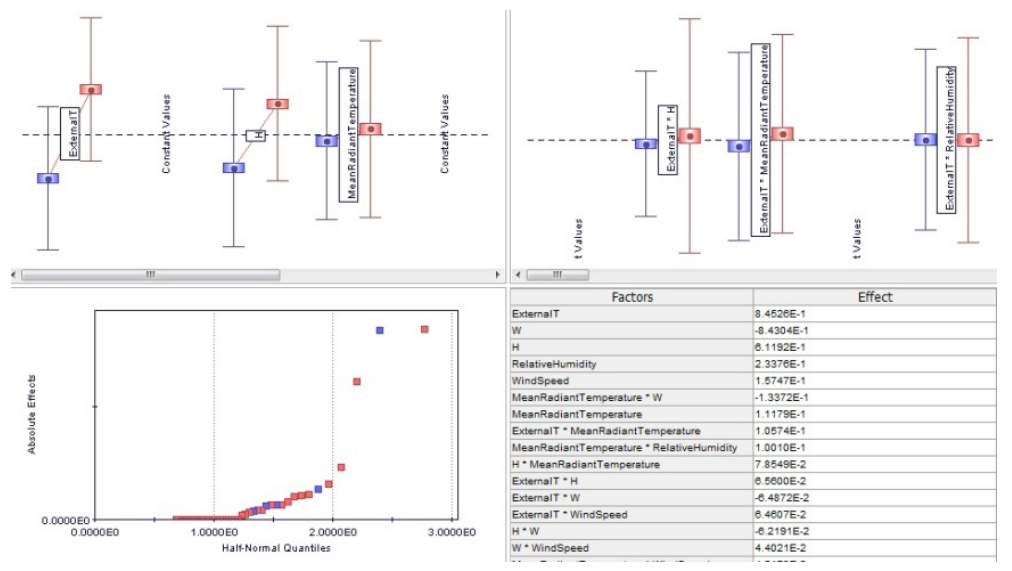

Figure 4: Factor analysis chart showing the coefficients of the best-fitting polynomial.

In Figure 4 starting from the left upper and rotating clockwise, we have:

- the effect of the individual variables,

- the effect of the product of the different variables (thus their combination),

- the quantitative effect of the factors,

- the effect of various factors from a graphical point of view. 
The results obtained show that temperature, building height, and street width are related to the best direct relationship (namely temperature and building height) or inverse relationship (street width).

To analyse the PPD behaviour, a program written in Wolfram Mathematica was used. The choice was determined by the fact that this software is a generalpurpose language suitable for our need to link the PPD evaluation with the geometrical $\mathrm{H} / \mathrm{W}$ ratio.

The rPPD (representative Predicted Percentage Dissatisfied) algorithm takes weather data for a specific region as input and calculates the PMV and the PPD for the RD.

The advantage of this instrument is its user-friendliness. In addition, it not only individually calculates all the meteorological parameters for an RD, the thermal comfort indices as well as the PMV and PPD, but it also links them to the geometrical factor (H/W ratio), highlighting their interdependence. Moreover, the interdependence of these quantities can be simulated in relation to different variables using a parametric optimization tool (e.g., ModeFRONTIER).

\section{The case study}

Analysis was carried out for the city of Ancona in the Marche Region in central Italy (Figure 5). Ancona is the largest city in the Marche Region, and in the past it has been intermittently destroyed by earthquakes and wars, forcing city districts to take new shapes without delay. "Modern" Ancona is laid out in a grid pattern of wide streets fronted by modern commercial buildings that are interspersed with ancient buildings and monuments. As mentioned before, urban density is the distribution of urban elements on the ground such as houses, urban alignments, empty plots, vegetation, etc. In addition, the space between buildings

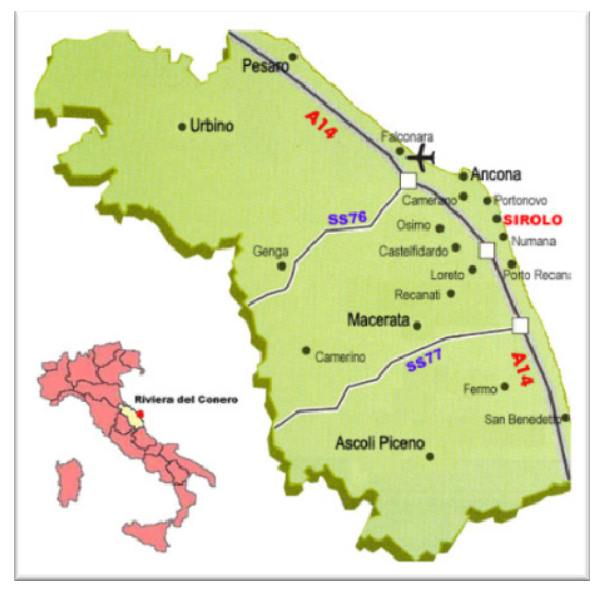

Figure 5: $\quad$ Map of the Marche Region, Italy. 
(including streets) and the average height of buildings also contribute to the urban density, which affects the local climate and the thermal comfort of the inhabitants.

Ancona's climate can be categorised as Mediterranean. It is mild, with summers that are warm but refreshed by a generous sea breeze and winters with regular seasonal rains. In mountainous areas, the summers are fresh and the winters are cold with ample snow possible.

The study area is generally occupied by medium- to low-scale buildings. The average building height is about 2-3 floors. There are few buildings that rise to 5-6 floors. Most of the buildings are rather old; a few modern buildings are being built. The urban density is not considered very high and the H/W ratio can be estimated at about 2 . The $\mathrm{H} / \mathrm{W}$ ratio affects shading patterns and solar radiation. Therefore, this $\mathrm{H} / \mathrm{W}$ ratio creates both positive and negative effects on the microclimate. In order to evaluate the representative day, monthly summer periods were analysed in the interval considered (2009-2012). During typical summer months (beginning in May and continuing through September), air temperature can become very high and the daily amplitude can be relatively wide. Despite the statistical rarity of a heat wave event, temperature records were set repeatedly in recent years. The meteorological parameters evaluated for the representative day and the metabolic variables considered for the case study are given in Table 2.

Table 2: $\quad$ Input variables.

\begin{tabular}{|l|l|}
\hline Variables & Range \\
\hline Temperature & $24.2-28^{\circ} \mathrm{C}$ \\
\hline Wind speed & $2.7-5.0 \mathrm{~m} / \mathrm{s}$ \\
\hline Relative humidity & $51.0-68.0 \%$ \\
\hline Street width & $3.0-8.0 \mathrm{~m}$ \\
\hline Building height & $6.5-15 \mathrm{~m}$ \\
\hline Clothing insulation & 0.5 clo \\
\hline Metabolic rate & 1.2 met \\
\hline
\end{tabular}

\section{Results and discussion}

The first simulation was carried out using the case study parameters (Table 2) and the Simplex algorithm to minimize the PMV. The results obtained are shown in Figure 6 and summarized in Table 3.

Table 3: Results of the simulation performed using the Simplex algorithm.

\begin{tabular}{|l|l|l|l|l|l|l|l|}
\hline $\mathrm{H}$ & $\mathrm{W}$ & $\mathrm{T}$ & $\begin{array}{l}\text { Metabolic } \\
\text { rate }\end{array}$ & $\begin{array}{l}\text { Relative } \\
\text { humidity }\end{array}$ & $\begin{array}{l}\text { Wind } \\
\text { speed }\end{array}$ & $\begin{array}{l}\text { Clothing } \\
\text { insulation }\end{array}$ & PMV \\
\hline $\begin{array}{l}6.514 \\
\mathrm{~m}\end{array}$ & $7.87 \mathrm{~m}$ & $24.3^{\circ} \mathrm{C}$ & $1.2 \mathrm{met}$ & $51.01 \%$ & $2.78 \mathrm{~m} / \mathrm{s}$ & 0.5 clo & 0.9 \\
\hline
\end{tabular}




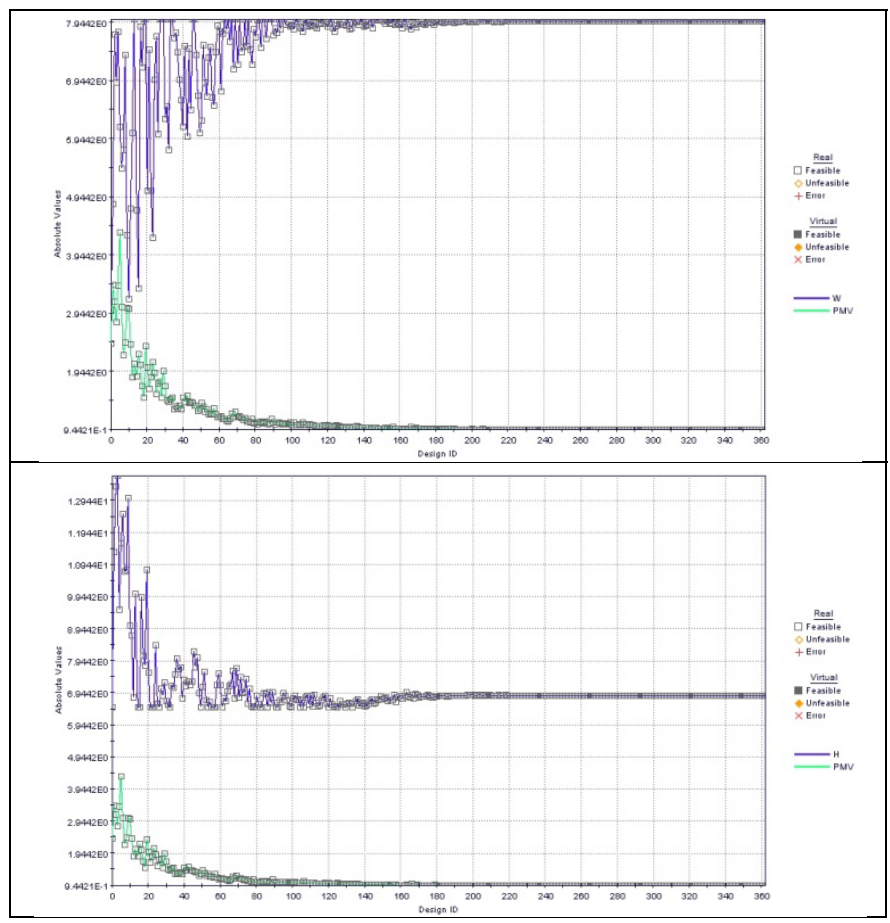

Figure 6: $\quad$ Street width (W) behaviour (up) and building height $(\mathrm{H})$ behaviour (down) for the PMV minimization using the Simplex algorithm.

In this simulation, we have assumed metabolic rate and clothing insulation to be constant. The minimum value for PMV (0.9) is reached for small height (6.5 $\mathrm{m})$ and large street width $(7.9 \mathrm{~m})$. As consequence, an important factor influencing outdoor comfort is urban geometry, which refers to the dimensions and spacing of buildings within a city. In fact, urban geometry influences wind flow, energy absorption, and a given surface's ability to emit long wave radiation back into space.

We decided to use a multi-objective optimization using an evolutionary algorithm and consider a larger range of building heights $(6.5-15 \mathrm{~m})$ and street widths (3-15 m) in order to evaluate the relationship between comfort parameters (e.g., PPD and PMV) and the geometrical H/W ratio. The results are summarized in Figure 7 and Table 4. It is clear from Table 4 how minimum Table 4: Results of the simulation performed using an evolutionary algorithm.

\begin{tabular}{|c|c|c|c|c|c|c|c|c|}
\hline $\mathrm{H}$ & $\mathrm{W}$ & $\mathrm{T}$ & $\begin{array}{c}\text { Metabolic } \\
\text { rate }\end{array}$ & $\begin{array}{c}\text { Relative } \\
\text { humidity }\end{array}$ & $\begin{array}{c}\text { Wind } \\
\text { speed }\end{array}$ & $\begin{array}{c}\text { Clothing } \\
\text { insulation }\end{array}$ & PMV & PPD \\
\hline $7.14 \mathrm{~m}$ & $14.88 \mathrm{n}$ & $24.4^{\circ} \mathrm{C}$ & $1.2 \mathrm{met}$ & $55.3 \%$ & $3.2 \mathrm{~m} / \mathrm{s}$ & $0.5 \mathrm{clo}$ & $4.39 \mathrm{E}-05$ & 5.00 \\
\hline
\end{tabular}


values for the PPD and PMV (high thermal comfort) are obtained for a large street width $(14.88 \mathrm{~m})$ and moderate building height $(7.1 \mathrm{~m})$. The H/W ratio can be considered an important parameter in determining the comfort level of open spaces.

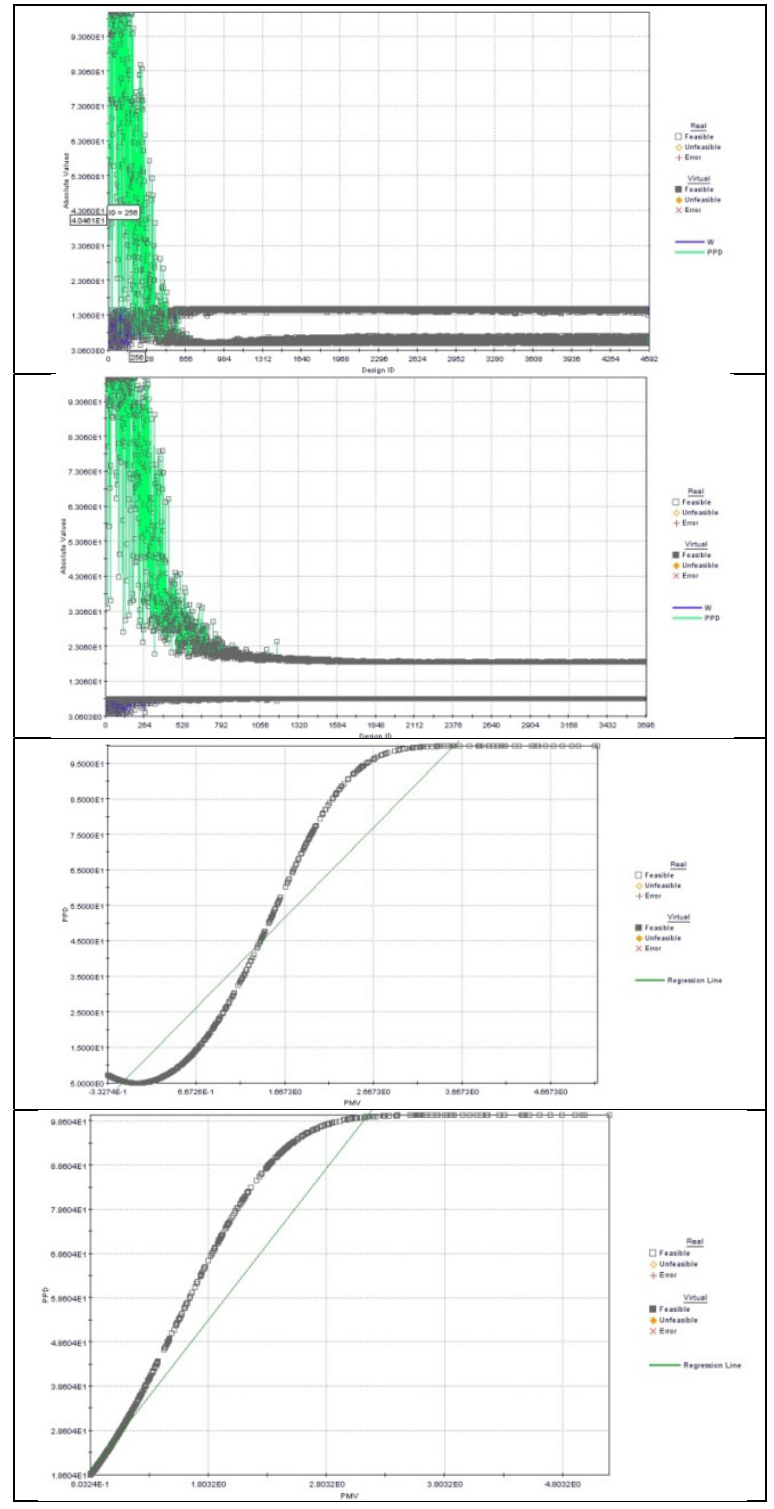

Figure 7: Simultaneous trends of the PMV and PPD, and their Pareto Frontiers. 


\section{Conclusions}

The primary goal in climate-conscious urban design is to achieve outdoor comfort. It is well known that urbanization tends to aggravate the negative effects of climate during summer seasons due to the increased thermal capacity, lack of water for evapotranspiration, and the "canyon effect". This generally causes thermal discomfort in Mediterranean cities during summer periods. Therefore, urban designers should prevent heat build up in the in cities and promote convective cooling at night. In this paper, we have considered how urban design can improve the thermal comfort of cities through urban form or urban geometry (e.g., street layout, building density, building morphology, height-to-width ratio). The building geometry was modified in terms of $\mathrm{H} / \mathrm{W}$ ratio and interesting results have been obtained. This can only be considered a first step because the design of thermally comfortable urban spaces deals with a collection of various issues. Therefore future research will include the effect of wind patterns on thermal comfort in urban environments, the materials used in buildings and their effect on outdoor thermal comfort, green spaces, viability, and so on.

\section{References}

[1] RUROS. Rediscovering the Urban Realm and Green Spaces, CRES, Building Department, 2004.

[2] Fanger, P.O. Thermal comfort, McGraw-Hill, New York, 1972.

[3] R. Cocci Grifoni, M. Pierantozzi, S. Tascini, G. Passerini, Assessing the representativeness of thermal comfort in outdoor spaces, Sustainable City 2012, Ecology and the Environment, pp. 835-846 2012.

[4] ISO 7730 Moderate thermal environments - determination of the PMV and PPD indices and specification of the conditions for thermal comfort, International Standards Organization, Geneva, 1994.

[5] Fanger P. and Toftum, J. Extension of the PMV model to non-airconditioned buildings in warm climates. Energy and Buildings, 34 pp. 533536, 2002.

[6] Krier, R. Urban Space, Academy Editions London, 1979.

[7] Landsberg, H.E., The Urban Climate. Academic Press Inc., New York, US, 1981.

[8] Oke, T.R., The energetic basis of the urban heat island, Quarterly Journal of the Royal Meteorological Society 108(455) pp. 1-24, 1982.

[9] Oke, T.R. The energetic basis of the urban heat island. Quarterly Journal of the Royal Meteorological Society, 108 pp. 1-24, 1982.

[10] Peterson, T.C. and Owen, T.W. Urban heat island assessment: metadata are important. Journal of climate, 18(14) pp. 2637-2646, 2005.

[11] Kim, Y.H. and Baik, J.J. Maximum urban heat island intensity in Seoul. Journal of Applied Meteorology, 41(6) pp. 651-659, 2002.

[12] Santamouris M., Energy and climate in the urban built environment, James \& James Ltd, London, UK, 2001. 